\title{
TEMPO E CAOS: A “IMAGINAÇÃo dOS POSSÍVEIS” E OS MÉdiA
}

\author{
Gustavo Castro \& Florence Dravet
}

\begin{abstract}
RESUMO
Este artigo propõe uma reflexão sobre a noção de tempo e suas relações com os média, a partir dos estudos da complexidade e numa perspetiva transdisciplinar. Iniciando com reflexões sobre narrativas literárias e cinematográficas, o nosso objetivo é perceber como a noção de tempo é mediadora da compreensão da realidade espaço/tempo e da perceção estética do mundo entre ordem e caos. Recorremos ao diálogo entre ciência e narrativa e ao pensamento da física moderna sobre os conceitos de tempo, ordem e caos. As nossas conclusões apontam para três ideias: 1) a constante rememoração da catástrofe é um tema íntimo obsessivo que se apresenta através da narrativa artística e mediática; 2) a expressão da obsessão catastrófica vem suprir parcialmente o afeto pelo horror da humanidade atual e 3) o imaginário da catástrofe atravessa tempo e espaço e é transdisciplinar.
\end{abstract}

\section{TIME AND CHAOS: THE "IMAGINATION OF POSSIBILITIES" AND THE MEDIA}

\begin{abstract}
This article proposes a reflection about the notion of time and its relation to the media based on the complex thinking paradigm and the transdisciplinary perspective. Departing from reflections about literary and cinematographic narratives, our objective is to examine how the notion of time mediates the concept of comprehension of space/time as well as of the aesthetic perception of the world between order and chaos. We relied on the dialogue between science and narrative and on modern physics for concepts of time, order and chaos. Our conclusions point to three ideas: 1) the constant remembrance of catastrophe is an obsessive intimate theme which presents itself through an artistic and mediatic narrative; 2) the expression of catastrophic obsession partially satisfies the current humanity's affection for horror and 3) the imaginary of catastrophe traverses time and space, being transdisciplinary.
\end{abstract}




\section{INTRODUÇÃO}

A relação entre tempo, média e caos integrou um programa de pesquisa desenvolvido nos chamados "estudos da complexidade". Deu-se a partir do desenvolvimento das ideias de "ordem a partir do ruído" ("ordre a partir du bruit") defendida por Henri Atlan (1992) e de "complexidade a partir da desordem", expressão utilizada pela primeira vez em 1948, por Warren Weaver, no célebre artigo "Science and complexity". O conceito de média tornou-se importante nos estudos da complexidade devido à perceção da "extrema quantidade de interações e de interferências entre um número muito grande de unidades que desafiam as nossas possibilidades de cálculo" (Pessis-Pasternak, 1993, p. 14).

Norbert Wiener e Ross Ashby, fundadores da cibernética, trabalharam para promover a noção de complexidade. John von Neuman acabou por revelar os vínculos que uniam os fenómenos de auto-organização aos das interações. Foi da perceção desses vínculos que Edgar Morin (1987) propôs um tetragrama (ordem/desordem/interação/ auto-organização) como articulação conceitual. Este permite conceber a comunicação como dialógica, regulada, primeiro, pela incerteza - tendência permanente ao caos e à desordem - próxima ao que Ilya Prigogine designou flutuação, isto é, um "mecanismo de irreversibilidade: uma vez estabelecida, ela difere do que era anteriormente" (Prigogine citado em Pessis-Pasternak, 1993, p. 43).

Neste artigo pretendemos pensar a noção de tempo, aproximando-a da de catástrofe. Pretendemos também pensar a noção de média, a partir de sua relação com a literatura.

A abordagem teórico-metodológica que seguimos no texto baseia-se na premissa segundo a qual narrativas, imaginários, poemas, romances e contos são discursos engendrados no nosso quotidiano e estão impregnados nos vários média. Referimo-nos, tal como proposto por Vicente Romano (1993), desde os primários (os de corpo e tempo presente), passando pelos secundários (aqueles em que o emissor se vale de um aparato técnico para enviar mensagens, alongando a perceção do tempo), aos terciários (em que emissor e recetor necessitam de aparatos técnicos e podem trocar mensagens sem estar simultaneamente presentes, encurtando o tempo e tornando a comunicação mais veloz).

O nosso método de apresentação e exploração do material é descritivo, interpretativo e crítico. Pretendemos privilegiar a análise do tempo, relacionando-o com o caos e a catástrofe presentes nas narrativas As cosmicômicas (1992) e Novas cosmicômicas (1995) de Italo Calvino, no filme Melancholia, de Lars Von Trier (2011) e, também, nas interpretações do físico e prémio Nobel de Química, Ilya Prigogine'. O nosso objetivo é mostrar como o conceito de tempo da literatura pode mediar a compreensão de realidade espaço/tempo e de mundo, podendo colaborar com o programa de pesquisa transdisciplinar dos estudos da complexidade.

(1917-2003). Físico-químico russo naturalizado belga, especialista em desequilíbrio termodinâmico. Prémio Nobel de Química (1977) pela sua contribuição ao estudo do desequilíbrio termodinâmico ou teoria das estruturas dissipativas. Foi fundador (1967) e primeiro diretor do llya Prigogine Center of Studies in Statistical Mechanics, Thermodynamics and Complex Systems, Universidade do Texas, Austin. 
Tanto do ponto de vista epistémico como metodológico, este artigo - que integra os estudos da complexidade - procura fazer dialogar com a ciência e arte, entendendo-as conjuntamente como campo de abertura e investimento na própria transdisciplinaridade. Sabemos que a literatura e o cinema contem sempre modelos de sociedade, se não a que aspiramos, ao menos a que temos e construímos. Elas reúnem em si a multiplicidade dos saberes, a busca ética e a cosmovisão estética da vida. Ciência e arte são saberes intercomunicantes, dois modos de observação do mundo que podem chegar a formar uma complementaridade ou a mesma unidade de conhecimento. Elas não podem seguir artificialmente separadas. Devem, antes, reintroduzir o Homem na complexidade do mundo. Se o saber científico alimenta a dúvida e cria hierarquias, ao fazer perguntas fundamentais, o saber artístico ilumina e aclara a realidade, colocando ou devolvendo o Homem ao seu contexto vital. A necessidade de fazer intercomunicar ciência e arte é a de reconhecer que uma e outra são sistemas de conhecimento úteis à sociedade. Enquanto a ciência lida com esforços conjuntos e sistemáticos para aumentar a experiência e desenvolver conceitos apropriados para a sua compreensão, a arte apresenta-nos esforços individuais, mais intuitivos, para evocar sentimentos que lembrem a globalidade da situação humana.

\section{A ordem do tempo segundo Ilya Prigogine e Italo Calvino}

A capacidade humana para imaginar o pior não tem limites. Sabemos que o tema da catástrofe não é novo. É, aliás, tão antigo quanto o do medo. Encontramos o assunto em, pelo menos, dois diálogos de Platão, no Timeu e no Crítias (escritos por volta do ano 360 a.C.). Em Crítias encontramos o relato a seguir. Conta-se que um antepassado do seu avô, que visitara o Egito e conversara com anciões, mestres da memória dos antigos, dizia que a catástrofe era algo do cosmos e, por isso mesmo, estava também em meio ao humano. Era um fenómeno que advinha de tempos em tempos. Inicialmente, diz Platão, acreditou-se que a catástrofe era um "mito", mas ela:

significa o declínio dos corpos que se movem em torno da Terra e nos céus; uma conflagração recorrente, que acontece em longos intervalos de tempo; quando isso acontece, aqueles que vivem nas montanhas e em outros lugares secos, estão mais sujeitos à destruição do que aqueles que vivem à margem dos rios, dos lagos ou do mar. Mas, por outro lado, quando os deuses purgam a terra pela água [e não pelo fogo, como Faetonte], então os pastores, os montanheses, são os sobreviventes e perecem os que vivem nas cidades, próximos aos rios e fontes, a beira-mar; são levados pelas enchentes, submergem no oceano. (...) Enquanto vocês [gregos] e outras nações mantêm escrituras e somente estes registros que interessam ao estado, no momento presente, ignoram que a pestilência [a catástrofe] pode estar vindo dos céus para dizimar todos e deixar apenas aqueles dentre vocês que são destituídos das letras e da educação e assim, deste modo, vocês têm de começar tudo novamente, como crianças, sem nada saber do 
que aconteceu nos tempos mais antigos, entre nós [o Egito] e entre vocês mesmos [gregos]. (Platão, 2010, p. 88)

Nesta citação percebemos que a "catástrofe" não é tratada como invenção, mas como algo que "acontece em longos intervalos de tempo". Aparece como realidade vivida pelos antigos. Que se revela, ora pela ação do fogo ora pela ação da água. Esses acontecimentos servem para que a Terra e a humanidade possam "começar tudo novamente como crianças". Os acontecimentos descritos neste fragmento de Platão alimentam, no mínimo há mais de dois milênios - por vias filosóficas - a imagem-ideia da catástrofe. Alimentam o pathos do fim presente em todos os seres humanos, ou seja, o afeto da entropia, a sensação do revés e às vezes a paixão pela queda.

Segundo Ilya Prigogine (1996) a "imaginação dos possíveis" e a especulação sobre o porvir são traço fundante da inteligência humana. O mesmo considera Antonio Maza no seu artigo sobre "O poder expressivo da teoria dos mundos nos videojogos" (2015) ao assumir que a teoria dos mundos possíveis está presente no contexto literário e narratológico em diversos autores e sob diversas formas: na realidade objetiva com textos de tipo histórico ou jornalístico, em textos de ficção verosímil, de mundos ficcionais não verosímeis e nas múltiplas interpretações de mundos atuais.

Enquanto egípcios e gregos imaginaram a destruição pelas águas e pelo fogo, o imaginário de Italo Calvino desenhou uma narrativa em que espaço e tempo se diluem e se esfacelam a todo instante em toda parte. O herói de As cosmicômicas² é Qfwfq, anamórfico, sua forma muda continuamente, ora avançando em complexidade, ora não. Este romance, escrito ao longo dos anos 1970, contém uma imagem-ideia de catástrofe, de ordem e de desordem que vale a pena analisar.

Nele, as coisas duram enquanto durar o sol, dá-nos a entender o herói-narrador. As pessoas são lisas e escovadas pelo vento das eras porque o tempo não passa de uma aposta: há o tempo de curta e de longa duração. Os acontecimentos fervilham com multiplicada densidade. O personagem anamórfico Qfwfq conhece a imortalidade. Está além do tempo sob a forma das metamorfoses: ele foi, no decurso de 50 milhões de anos, uma sequência de dinossauros diversos; experimentou também formas como a do girino, a do átomo, do cavalo, de um ancião; conheceu o império de Justiniano, viu o bicho-da-seda ser levado da China à Constantinopla, entre outras peripécias. Outro personagem, como seu irmão, Rwzfs, não quis experimentar as formas, permanecendo níquel por toda a vida. Sr. Hnw, por sua vez, passou a existência aspirando transformar-se em cavalo. Qfwfq considera o ornitorrinco, a girafa, o crocodilo e o dinossauro, sublimes. "A memória dos mundos", título da primeira parte de Novas cosmicômicas [Tempo zero em outras traduções], descreve histórias entremeadas de reflexões cosmológicas, filosóficas e existenciais:

interrogávamos qual o destino do universo, e os oráculos da termodinâmica nos respondiam: toda a forma existente se desfará numa labareda de calor;

${ }^{2}$ Italo Calvino publicou também a continuidade das aventuras de Qfwfq no Novas cosmicômicas (1995) a que faremos referência aqui. 
não há presença que se salve da desordem sem retorno dos corpúsculos; o tempo é uma catástrofe perpétua e irreversível. (Calvino, 1995, p. 127)

A catástrofe aparece como razão para a necessidade de apreço à ordem. Encontrar o equilíbrio no universo, a forma naquilo que parece sem forma, não é tarefa fácil. Qfwfq prefere arriscar-se na geometria dos cristais, das relações amorosas, números, jogos e espirais. A primazia da ordem deve ser dada ao modelo amoroso, aquele que possua Eros em sua estrutura. A ordem buscada deve ser aquela na qual regularidade e tensão contrapõem-se e justapõem-se para a manutenção do equilíbrio. Observemos cubos, octaedros, prismas e figuras diáfanas. A ordem assemelha-se aos cristais, que são esculpidos pelo tempo e lapidados por características de vigor, ímpeto e tensão.

A noção de uma ordem pela tensão aparece na declaração de amor que Qfwfq faz a Vug, personagem que é um cristal. O cristal, para Qfwfq, é a imagem da perfeição ou o sonho de perfeição da matéria; a ordem refletida (esculpida) numa imagem mineral. A contemplação da ordem faz Qfwfq admitir que, cedo ou tarde, o sonho de perfeição estorva e pode também se esfumaçar no ar, desfazendo-se "num esfiampado remendo da desagregação" (Calvino, 1995, p. 44). É quando surge a catástrofe. Tudo rui. Diante do cenário da catástrofe, Qfwfq escolhe, preferencialmente, a ordem, pois ela propicia a sensação de temor e felicidade. A felicidade advém da descoberta de que as substâncias são teleológicas. Buscam algo à perfeição, em especial, buscam uma forma eficaz, útil e bela. Temor por perceber na variedade das ordens as escalas crescentes de desordem. Escalas que, cedo ou tarde, comprometerão a felicidade da busca.

Vug, a mulher-cristal é a imagem-reflexo do mundo, contém bilhões de lados e ângulos, conta-nos Qfwfq. É um sólido destinado a ampliar-se em perspectivas, transparências, níveis e lados. Com a ordem não pode haver embustes, diz. Não se pode tentar fugir à dramaticidade do tempo ou ficar obcecado com a ideia de uma ordem perfeita. Qfwfq aprende, pouco a pouco, as lições do cristal. Vug é quem lhe ensina: "admitir que a verdadeira ordem é a que traz em si a impureza, a destruição" (Calvino, 1995, p. 49).

No conto "Os cristais", Qfwfq narra os tempos remotos em que namorou Vug, Qfwfq comprou um relógio de pulso. Pretendia comparar o movimento dos ponteiros ao movimento das estações, das luas, dos ciclos da vida e da morte. Seguir o tempo orientando-se pelos ponteiros do relógio era importante para manter-se no jogo do mundo e dos homens, onde as coisas acontecem com hora marcada: pegar o trem, descer na estação correta, entrar pontualmente no trabalho, oficiar regularmente o cotidiano, cumprir compromissos, são formas do tempo cronométrico. Mas aqueles ponteiros podem muito bem enganar-nos sobre o que é tempo. Os ponteiros indicam um erro, observa Qfwfq, o que significa fingir uma ordem na poeira, uma regularidade no sistema, porque toda ordem, seja ela qual for, logo se esboroa. O relógio de pulso ajuda-nos a simular uma ordem e uma regularidade onde não existe nem uma coisa nem outra. Com ou sem relógio, a ordem do tempo é desintegradora. Isto os ponteiros não mostram. É preciso fugir (confessa na história: "A implosão") que "está a fugir à catástrofe do tempo". Reconhece: "todo o percurso do tempo se dirige para o desastre num sentido ou no sentido 
contrário e o seu intersecar-se não forma uma rede de linhas reguladas por trocas e por desvios, mas sim um enredo, num emaranhado" (Calvino, 1995, pp. 129-130).

O tempo conta uma história que só é possível de ser percebida e desvendada se a registarmos mediante a narração. Percebemos, ao longo da sua trajetória, que esta mesma narração se desgasta a ponto de ter que mudar constantemente, para manter suas correlações internas e prosseguir, ou dar-se por encerrada. Qfwfq dedica-se preferencialmente a entender a ordem através do caos. Ao associar ordem e Eros, consegue uma aproximação, à primeira vista, de termos contraditórios. Seguimos a concepção errónea, diz ele, na qual Eros se associa à desordem. O motivo desse erro estaria no facto de ser somente na dinâmica propiciada por Eros que a ordem pode ser amada. A associação entre Eros e ordem esconde a ambição pela perfeição e simetria entre elementos divergentes.

A ordem apresenta-se enredada, simultaneamente, de Eros e de desordem. Eros, por sua vez, é simultaneamente ordem e caos. A pureza (do cristal e da ordem) só é possível devido às falhas, ruturas e impurezas. Somente a dinâmica de Eros (ou o amor por Vug) que poderia ter-lhe revelado isto: o par ordem-caos é o que nos faz entender como funciona, se reorganiza e se lapida um sistema como o cristal. Mesmo a pureza do cristal não deixa de transparecer a mancha, a falha e a corrosão que o tempo inflige sobre ele. Para continuar a manter o ímpeto e o vigor, a matéria deve operar na catástrofe e na degradação, o que na ótica de Qfwfq é o mesmo que lapidação. Aparar arestas significa polir a forma. O relógio de pulso não consegue cronometrar, nem o enredo do tempo nem a lapidação do cristal. O tempo do relógio de pulso não se afiniza com o tempo do cristal. Até porque o relógio cai, quebra, enferruja ou, simplesmente, para de funcionar. Qfwfq convence-se de que as irregularidades fazem parte de:

uma estrutura regular muito mais vasta, em que a cada assimetria que julgávamos observar correspondia na realidade a uma rede de simetrias tão complicadas que nem dávamos por ela, tentava calcular quantos bilhões de lados e de ângulos diedros devia ter este cristal labiríntico. (Calvino, 1995, p. 49)

Esta noção de tempo de Italo Calvino chamou a atenção de Ilya Prigogine para quem o conjunto das narrativas de As cosmicômicas faz lembrar os contos árabes em que cada história se encaixa em outras histórias. "A história da matéria encaixa-se na história cosmológica, a história da vida na história da matéria. $\mathrm{E}$, por fim, nossas próprias vidas estão mergulhadas na história da sociedade" (Prigogine, 1996, p. 192). O autor fez menção ao livro como resultado da "imaginação dos possíveis":

Italo Calvino escreveu uma deliciosa coletânea de novelas Cosmicômicas nas quais imaginava seres que vivem num estágio muito precoce do universo. Eles se reúnem e se lembram ainda hoje da época difícil em que o universo era tão pequeno que seus corpos o preenchiam complemente. A imaginação dos possíveis, a especulação sobre o que poderia ter sido é um 
dos traços fundamentais da inteligência humana. Que teria sido da história da física se Newton tivesse sido um membro dessa comunidade precoce? Ele teria observado o nascimento e a decomposição das partículas, a aniquilação mútua da matéria e antimatéria. O universo ter-se-ia mostrado a ele desde o começo como um sistema distante do equilíbrio, com suas instabilidade e bifurcações. (Prigogine, 1996, p. 194)

Ao ponderar aos "oráculos da termodinâmica", Qfwfq apresenta um universo distante do equilíbrio. A visão da protagonista, como vimos, perspetivada a partir de Vug, é a de uma "ordem que traz em si a destruição". Ao consultar os oráculos, interrogando-os sobre o universo, obtém a resposta de que "o tempo é uma catástrofe perpétua e irreversível". Prigogine identificou nestas noções espaço-temporais presentes na comunidade de Qfwfq, as bifurcações e desequilíbrios do universo. As partículas elementares parecem ser insensíveis à ação do tempo, muito embora, ao adquirirem uma forma qualquer, passem pelo efeito temporal de degeneração.

Foi Prigogine quem primeiro duvidou, nos domínios da pesquisa científica, da hipótese segundo a qual tempo é uma ilusão. Segundo ele: "é Einstein que encarna com a maior força a ambição de eliminar o tempo" (Prigogine \& Stengers, 1997, p. 210). A negação do tempo sempre foi uma tentação. "Tanto para Einstein, o físico, quanto para Borges, o poeta" (Prigogine, 1996, p. 197). Negar o tempo significa negar a própria realidade, considerando-a uma ilusão. "Tempo e realidade estão irredutivelmente ligados. Negar o tempo pode parecer um consolo ou parecer com o triunfo da razão humana, é sempre uma negação da realidade" (Prigogine, 1996, p. 197). A conceção de que "o tempo é uma ilusão" foi incorporada nas leis fundamentais da física e passou a desautorizar, desde então, uma distinção entre passado e futuro que desempenham papéis diferentes, não simétricos. Coube ao observador, ao ter o seu papel destacado com o advento da teoria quântica, ser o responsável pela quebra da simetria temporal, conforme esclarece o físico: "hoje, a física não nega mais o tempo. Reconhece o tempo irreversível das evoluções para o equilíbrio, o tempo ritmado das estruturas cuja pulsão se alimenta do mundo que as atravessa" (Prigogine \& Stengers 1997, p. 211).

Há mais do que uma aceitação do tempo. O que ocorre é uma redescoberta do tempo, um pensamento que trata o tempo como o elemento modificador e dialógico, por excelência, entre ciência, cultura e sociedade. Podemos dizer que a literatura de Marcel Proust, Jorge Luís Borges e Italo Calvino, só para nos atermos a esses três mestres, é perpassada pela ideia de tempo. Tal redescoberta trouxe consigo também a garantia de que noções, tais como a de flecha do tempo ou catástrofe, possuem papel construtivo fundamental que nos fornece a imagem de universo em constante realização, evolutivo e assimétrico. Revela-nos também o seu elemento narrativo, pois o tempo está constantemente a contar uma história. Esta redescoberta é também fundamental para Edgar Morin:

reabilitar unicamente o tempo não é suficiente; o novo universo, ao nascer, fez-nos descobrir a sua complexidade. O tempo é uno e múltiplo. É simultaneamente contínuo e descontínuo, eventual, agitado por rupturas e sobressaltos que rompem o seu fio e eventualmente recriam, noutros sítios, 
outros fios. Este tempo é, no mesmo momento, o tempo das derivações e dispersões, o tempo das morfogêneses e dos desenvolvimentos. (Morin 1987, p. 85)

A história contada pelo universo e que a física reiteradamente busca decifrar, assemelha-se, na visão de Prigogine, a um romance como, o das "As mil e uma noites" (Prigogine \& Morin, 1998, p. 232): uma intricada cadeia de enredos e tempos internos a perpassar cada corpo, seja ele um grupo social ou um livro. Cada um deles "é constituído por uma pluralidade de tempos ramificados um nos outros segundo articulações sutis e múltiplas" (Prigogine \& Stengers, 1997, p. 121).

As conclusões das pesquisas formais de Prigogine apresentadas, tanto no livro A nova aliança, com Isabelle Stengers (1997), como na obra O fim das certezas (1996), mostram-nos que persiste a irresolução do paradoxo do tempo: "o tempo em que vivemos é essencialmente irreversível, enquanto nos objetos físicos simples - um pêndulo ou o sistema planetário - não se vê essa flecha do tempo (Prigogine citado em Pessis-Pasternak, 1993, p. 45).

Segundo Prigogine, a tomada de consciência desse paradoxo aparece primeiro na teoria darwiniana, já que esta foi a primeira a tratar da evolução dos organismos, portanto, da irreversibilidade. Em seguida há o aparecimento do segundo princípio da termodinâmica, formulado por Rudolf Clausius³, em 1865, que trata da entropia no universo. Os dois princípios fundamentais da termodinâmica são: [1] "a energia do universo é constante" e [2] "a entropia do universo cresce na direção de um máximo". A natureza apresenta-nos, diz o autor, processos reversíveis e irreversíveis:

Por um lado, há o tempo dos relógios, das trajetórias das dinâmicas clássicas, o tempo da comunicação. Esse tempo é de alguma forma exterior a nós, que emitimos e recebemos signos. É um tempo que medimos com nossos relógios, mas que não faz parte do nosso corpo vivido. Há por outro lado o tempo estrutural, que chamei de interno, marcado pelo irreversível e pelas flutuações, próximo ao "tempo-invenção" de Bergson. (Prigogine citado em Pessis-Pasternak, 1993, p. 42)

A tradicional cronologia da teoria do Big Bang pressupõe a existência de um tempo zero, a partir do qual os relógios cósmicos tenham começado a funcionar. Evento para o qual os físicos como Hubert Reeves e Ilya Prigogine recomendam cautela. Essa forma de contar o tempo não considera a possibilidade de um tempo anterior a este tempo zero. É justamente a ideia do tempo zero o que alimenta o enredo dos romances de Italo Calvino. No conto "Os cristais", o relógio de pulso de Qfwfq não lhe assegura que a ordem do tempo pode ser fixada nas escalas dos três ponteiros, do mesmo modo que no conto "Ao nascer do dia", o personagem narra a criação do universo como um evento emergindo num clarão de dentro de um tempo-espaço já preexistente. Neste aspeto, Calvino

\footnotetext{
${ }^{3}$ Rudolf Clausius (1822-1888) físico e matemático alemão, considerado um dos fundadores da ciência da termodinâmica. Em seu artigo mais importante, Sobre a teoria mecânica do calor, publicado em 1850, expôs pela primeira vez as ideias básicas da segunda lei da termodinâmica. Em 1865 introduziu o conceito de entropia.
} 
(ao lidar com o imaginário) e Prigogine (pesquisa científica), aproximam-se: "o tempo precede a existência. Acho mais natural supor que o nascimento do nosso universo é um evento na história do cosmo e que devemos, pois, atribuir a este um tempo que precede o próprio nascimento de nosso universo (Prigogine, 1996, p. 169).

A história, o ser vivo e a sociedade não podem mais ser reduzidos à noção de tempo único. Agora a multiplicidade de tempos constitui-se como fator criativo, perturbador do sistema; perturbação que pode tanto gerar como degradar as coisas. Prigogine encontra na ideia do clinâmen de Lucrécio 4 uma inspiração. Ele é o elemento perturbador que anuncia a "guinada" dos átomos no mundo. Esse elemento é uma fonte de instabilidade que anuncia que o processo e o devir são constitutivos da existência física. Um mundo no qual os seres vivos e as coisas aparentemente inanimadas como a pedra, o plástico e o sabão interagem de modo dinâmico e podem nascer, morrer e evoluir. A irreversibilidade do tempo relaciona-se, assim, com os níveis de correlações e coerências do sistema e leva em conta a sua capacidade de resistir e se auto-organizar através desta tensão perturbadora. A perspectiva de que todas as coisas estão submetidas às pequenas e grandes catástrofes, ou seja, às instabilidades do tempo, aparecem nos personagens de Calvino como exortação a uma tomada de consciência e de decisões, requerida pelo exercício da liberdade. As escolhas da vida são também irreversíveis.

\section{CATÁSTROFE, CAOS E IMAGINÁRIO}

Assim como a literatura, o cinema também explora a "imaginação dos possíveis". O cinema de catástrofe ${ }^{5}$ já mostrou nossa humanidade (e no nosso planeta) destruído por guerras (tribais, sazonais e interestelares), bombas, monstros, cataclismos diversos como invernos polares, vulcões, meteoros, desastres naturais e provocados. O cinema mostra espetacularmente multidões devastadas em segundos, cidades arrasadas num passe de mágica e continentes que se partem ao meio. O que significa essa constante retomada do tema pela ficção e pelos documentários especulativos do Discovery Channel? Os noticiários da TV tornam-se urubus que sobrevoam a miséria, atentados terroristas, bugs, mudanças climáticas, o 21.12.2012, enfim, onde está a catástrofe, ali estarão os média. Por que investimos tantos olhares nesta direção? Como continuar a encarar os neo-messianismos ${ }^{6}$ e os neo-sebastianismos ${ }^{7}$ da nossa época que não param de insistir e alertar que o fim está próximo ou que o Homem "irá voltar"?

\footnotetext{
4 Tito Lucrécio Caro (99 a. C.). Poeta e filósofo, viveu 44 anos. Em De rerum natura Lucrécio apresenta a teoria de que a luz visível seria composta de pequenas partículas.

${ }_{5}^{5}$ Chamamos "cinema de catástrofe" ao conjunto de filmes produzidos com o tema do fim da humanidade (ou de parte dela) ou do planeta terra.

${ }^{6}$ Crença do retorno de um enviado divino. Palavra que deriva de Messias (mashiah em hebraico, christós em grego). Termo utilizado para caracterizar movimentos ou atitudes movidas pelo afeto de "escolha" ou de "eleição".

7 Movimento místico-secular ocorrido em Portugal na segunda metade do século XVI. Com o desaparecimento do rei D. Sebastião na batalha de Alcácer-Quibir, em 1578 e, por falta de herdeiros, o trono português terminou nas mãos do rei Felipe II da casa de Habsburgo. O sebastianismo é uma forma de messianismo adaptado às condições lusas e à cultura nordestina do Brasil. Significa inconformidade com a situação política vigente e expectativa de salvação, ainda que miraculosa.
} 
A palavra "catástrofe" vem do grego e significa, literalmente, "virada para baixo" (kata + sthophé). Outra tradução possível é "desabamento", ou "desastre"; ou mesmo no hebraico shoah, especialmente apto no contexto. A catástrofe é por definição um evento que provoca um trauma, outra palavra grega que quer dizer "ferimento". "Trauma" deriva de uma raiz indo-europeia com dois sentidos: "friccionar, triturar, perfurar"; mas também "suplantar", "passar através". Nesta contradição - uma coisa que tritura, perfura, mas que, ao mesmo tempo, é o que nos faz suplantá-la, já se revela, mais uma vez, o paradoxo da experiência catastrófica, que por isso mesmo não se deixa apanhar por formas simples de narrativa. (Nestrovski \& Seligman-Silva, 2000, p. 8)

Podemos, então, dizer que o imaginário dos atores sociais, assim como o cinema de catástrofe, comporta/guarda/realimenta a imagem arquetípica da ferida e do ferimento, guarda a "virada para baixo" e o "trauma". A ferida trágica não pode ser definitivamente curada. Ela está em nossa memória arcaica e, de tempos em tempos, ressurge. Filmes sobre o holocausto dominaram o imaginário cinematográfico de destruição do século XX para lembrar que um sangue ruim correu pelas veias do século. $O$ cinema agente de nossa memória arcaica - reviveu e encenou dores das quais não conseguimos livrar-nos enquanto sociedade.

O cinema e a literatura mostraram-nos também a vida psíquica: a subjetividade e os afetos. Inclusive, a história de muitos artistas é uma história de loucuras, tragédias, sofrimentos, tormentos e desesperos, portanto, temas da catástrofe íntima. O cinema e a literatura, neste sentido, são dois infinitos subjetivos. Não cessam de contar parábolas sobre o passado e o futuro. Trata-se de uma antiga pedagogia do presente: a narrativa como reatualização do essencial. A arte mostra-nos que a catástrofe transita da esfera cósmica para a da interioridade humana, como se o caos estivesse continuamente a renovar-se. A catástrofe "está em nosso meio", diz Platão no Crítias. Queremos dizer com isso que o tema reaparece em toda parte, semelhante aos temas cosmológicos. É um tema singular, pessoal, concordando aqui com o que observou Morin:

nosso universo é catastrófico desde o início. Desde a deflagração formidável que o fez nascer, ele é dominado pelas forças de deslocações, de desintegrações, de colisões, de explosões e de destruição. É constituído no e pelo genocídio da antimatéria pela matéria, e sua aventura aterradora prossegue nas devastações, nos massacres e nas dilapidações singulares. A saída é impiedosa. Tudo morrerá. (Morin, 1997, p. 271)

Em 2011, Lars Von Trier lançou o filme Melancholia e vimos novamente o "fim dos tempos". O filme retrata duas irmãs (uma noiva, Justine - Kirsten Dunsy) e outra já mãe, Claire (Charlotte Gainsbourg), com o seu marido John (Kiefer Sutherland), nas suas relações familiares e interpessoais e na sua dimensão mental. Passa-se em dois momentos, o primeiro, antes de se saber que o Mundo vai acabar, no casamento falhado de Justine, 
que é aí o centro das atenções; o segundo, quando o Apocalipse terrestre já é quase uma certeza e é dado destaque, acima de tudo, ao "desmoronar" do mundo pessoal de Claire. Von Trier opta por iniciar o filme precisamente com o momento em que a Terra embate, sendo destruída, com Melancolia, planeta imaginário. Explicou à imprensa que o fez precisamente porque queria deslocar a atenção do espectador do acontecimento em si para o cenário humano subjacente. Justine (o nome da noiva) é uma referência à "Justine", do Marquês de Sade; a música do filme é essencialmente "Tristão e Isolda", de Richard Wagner.

Vimos ali o planeta Terra a ser atingido por outro planeta, chamado Melancolia. No filme, o ceticismo da ciência e dos média são evidentes, visão não compartilhada pelas mulheres e os cavalos que, na sua intimidade com o cosmos, conseguem perceber o que está por vir. Ali, semelhante ao romance de Italo Calvino, a catástrofe acontece tanto na ordem cosmológica, como na ordem pessoal. No filme vemos Justine (Kirsten Dunsy) encarar a câmara com olhar de tristeza enquanto pássaros mortos caem a sua volta; Claire (Charlotte Gainsbourg) carrega o filho com dificuldade através de um campo de golfe. Kirsten, vestida de noiva, aparece amarrada a fios de lã e, depois, a ser levada pela correnteza; um cavalo cai em silêncio. Tudo rui.

O cinema está impregnado de pathos do fim. O tema do holocausto, por exemplo, é uma constante na cinematografia mundial. Alguns ditadores também ficaram fascinados por imagens cinematográficas. Adolf Hitler foi um deles. Hans Jurgen Syberberg conta-nos em Hitler, um filme da Alemanha (1978), que, até iniciar a guerra, o Führer assistia a vários filmes todos os dias. Depois o início da guerra, só atualidades filmadas na frente de batalha. Ficamos a saber que cada regimento do exército alemão tinha uma companhia de propaganda, cuja função era cinematográfica. Esta ação permitia que factos ocorridos no front se transformassem em documentários jornalísticos. Num discurso de Joseph Goebbels, no fim da guerra, ouvimo-lo dizer: "senhores, em cem anos mostrarão o filme que descreverá os espantosos dias que vivemos atualmente. Não querem representar um papel neste filme? Cada um tem a oportunidade de escolher o seu papel" (Nap, 1977, s.p.).

Hans Syberberg mostra-nos que a Alemanha perdeu a guerra, mas Hitler triunfou, ou seja, conseguiu impregnar ou imprimir a sua lógica diabólica ao século, fazendo da política arte para as massas. Ele viu na destruição uma obra de arte total: "Hitler o mais pretensioso dos cineastas. É preciso vê-lo como um cineasta", diz Peter Pal Pelbart (2000, p. 178). Segundo Pelbart, Hitler, um filme da Alemanha, não é um documentário sobre uma catástrofe, mas sobre como a catástrofe se produziu como filme, a catástrofe como mise-en-scène, como megaprodução política cinematográfica do III Reich.

Os filmes Melancolia e Hitler, um filme da Alemanha retomam o fio temático da catástrofe no nosso tempo pela via cinematográfica, atualizando a memória arcaica sobre a catástrofe. Assim como a arte, a ciência e a filosofia também atualizam a nossa memória arcaica, como vemos em propostas como a Teoria do Caos ou a Teoria da Catástrofe, de René Thom (1983), a Teoria da Complexidade de Edgar Morin (1987), além da teoria dos média de Vilém Flusser. Cabe destacar que este último, em Vampyroteuthis infernalis 
(2011), designou como "as três catástrofes" o processo de hominização, de civilização e o dos "furacões da mídia" (apesar de dizer que este terceiro momento está ainda sem nome), ele refere-se obviamente ao campo da informação, da imprensa, da publicidade, do cinema, enfim, das trocas "velozes e furiosas" dos sistemas mediático-culturais.

A primeira catástrofe foi a hominização, a descida das árvores, o tornar-se bípede e ereto, o deslocar-se nômade pela terra. A segunda catástrofe foi a civilizacional, a criação de aldeias e cidades, em torno das quais os homens foram domesticados e passaram a cultivar vegetais e criar galinhas. Em latim, os verbos sedere (sentar) e possedere (possuir) são irmãos e mostram claramente a proximidade semântica entre sentar e possuir. Dez mil anos depois dos primeiros assentamentos surge a escrita e os sistemas lógicos dela advindos. Vivemos agora o advento da terceira grande catástrofe, que nos obriga a navegar, surfar, perambular, viajar, enfim, dar o fora, pelas redes virtuais, pelas paisagens sintéticas, pelos cenários e ambientes retangulares, enfim, pelas imagens visuais e sonoras dos média.

O imaginário da catástrofe remete-nos para dois imaginários opostos e complementares: do finito e do infinito. Sobre o imaginário do finito encontramos algumas ideias-imagens agrupadas nas representações de entropia, de morte, de desaparecimento, de cemitério, de sepultura, de abismo, de crepúsculo e de imanência absoluta. No imaginário do infinito temos outras imagens: $0 \infty$ (lemniscata $\left.^{8}\right)$, que é o Ouroboros ${ }^{9}$ duplicado $(\mathrm{O}+\mathrm{O})$, a cobra que come o próprio rabo, representação do movimento contínuo e perpétuo, a imagem da liberdade, dos espaços abertos, a impossibilidade de registo como os grãos de areia, as folhas e das estrelas. Esses imaginários (finito e infinito) opõem-se e complementam-se revelando-nos, por sua vez, os dois sentidos da catástrofe: o negativo, de entropia, fim, término; e o positivo, de suplantação, criação e recriação indeterminadas.

Não queremos que o fim esteja próximo, padecemos da agonia das conclusões. Aquilo que os terapeutas chamam "síndrome da procrastinação"10. O que Nestrovski e Seligman-Silva denominaram "paradoxo da catástrofe" anuncia a presença do trauma, o eco da dor e da ferida, mas também a ultrapassagem e sua transcendência. Este paradoxo revela a nossa imensa capacidade de recomeçar do zero. Observamos uma relação de proximidade entre as noções de caos e de catástrofe. A palavra Caos deriva de Káos, Khraíen, quer dizer abrir, entreabrir: "significa abismo insondável, conceito acompanhado por uma esfera sígnica que o personifica como vazio primordial, anterior à criação, enfim, como rudis indigestaques moles - massa informe e confusa - capaz de conter a semente de todas as coisas (Naves citado em Castro, Galeno \& Silva, 2003, p. 82).

\footnotetext{
${ }^{8}$ Do latim Lemniscus: faixa suspensa. Curva que tem curva a forma similar ao numeral 8 e o símbolo de infinito. A razão dessa curva geométrica assumir tal significado é em função da sua linha contínua.

9 Ouroboros (ou oroboro ou ainda uróboro) é um símbolo representado por uma serpente, ou um dragão, que morde a própria cauda. O nome vem do grego antigo: oúpá (oura) significa "cauda" e ßópos (boros), que significa "devora". Assim, a palavra designa "aquele que devora a própria cauda". Sua representação simboliza a eternidade. Está relacionado com a alquimia e é, por vezes, representado como dois animais míticos, mordendo o rabo um do outro. É possível que o símbolo matemático do infinito $(\infty)$ tenha tido sua origem a partir da imagem de dois ouroboros, lado a lado.

10 Refere-se à incapacidade de concluir. Atitude sistemática de "deixar para depois" mesmo que essas tarefas se tornem urgentes e inadiáveis.
} 
O caos (assim como a catástrofe) tira o fundamento, substituindo-o. A catástrofe traz a incerteza e a "virada para baixo". A nossa civilização parece sofrer do que Peter Sloterdijk (2012) chamou "complexo de catastrofilia". Significa um sintoma psicopolítico de sufocamento da atmosfera social que carrega o nosso tempo até o insuportável com tensões esquizoides e ambivalências. Passamos a encarar a realidade como paranoica, como perturbação coletiva do sentimento vital, pela qual as energias da vida se deslocam para a simpatia do que é catastrófico, apocalíptico e dotado de violência espetacular.

A literatura, o cinema, as artes e os média, como um todo, mostram-nos que estamos submetidos a tempestades afetivas, informacionais e de consciência que se apoderam do grande público, via explosões de alegria, de violência e, às vezes - como no Brasil em épocas de Copa do Mundo - de emoção nacional; em outros momentos, o grande público apodera-se do prazer e da angústia, da embriaguez de destino e da felicidade religiosa. As ideias de felicidade e sucesso são formas de fugir do fracasso. $O$ "complexo de catastrofilia" corrobora o pathos do fim, essa incapacidade de concluir ou atitude sistemática de "deixar para depois" mesmo que essas tarefas se tornem urgentes e inadiáveis.

O volume da informação dos média impõe-se como uma forma de consciência que aprende a escolher o escândalo como modo de vida e a catástrofe como ruído de fundo, diz Peter Sloterdijk (2012, p. 412). Um exemplo: quando pensamos a questão criminal da maneira como é posta na nossa sociedade, mas também da maneira como é posta no âmbito das artes - literatura, teatro e cinema - deparamo-nos com um excesso de esquemas criminais diversos que nos dá a impressão de esgotamento das fórmulas de imaginar torturas, assassinatos, esquartejamentos, violências várias. Criamos sempre e a cada dia novas formas de tensão; situações de tensão, que não querem mais ser comunicadas e dissolvidas, mas sim, lançadas pelos ares: "a tendência aponta para caminhos brutais de saída de tensão - para uma inclinação a arrebentar, ao massacre, à explosão, à catástrofe" (p. 410). O trágico deslocou-se para o mundo do jornalismo, não deixando totalmente o campo artístico, como observamos nas reencenações das tragédias gregas e no cinema de catástrofe.

\section{O FIM QUE É RECOMEÇO: CONCLUSÃo}

O nosso objetivo neste artigo consistiu em perceber como a noção de tempo na literatura e no cinema pode aproximar-se daquela da física e ambas subsidiarem um modo percetivo/estético próprio de mediação com o mundo como caos e ordem. Vimos como a noção de tempo é mediadora da compreensão da realidade espaço/tempo, seja do ponto de vista científico (físico), seja do ponto de vista artístico (ficcional). A "imaginação dos possíveis" de Calvino descrita por Prigogine revela um traço fundante de abertura conceitual e de exercício da transdisciplinaridade. É, portanto, um traço da inteligência humana. A imaginação de Italo Calvino desenhou uma narrativa em que espaço e tempo se diluem de modo anamórfico, dinâmico, flutuante e auto-organizado. 
A forma do tempo aproxima-se da própria forma de Qfwfq, muda continuamente, ora avançando em complexidade, ora não. Estas narrativas, escritas ao longo dos anos 1970, contêm uma imagem-ideia de comunicação e de média que acompanha essa flutuação, dinâmica, movimento e incerteza. Neste sentido, cabe aos média, qualquer que seja, abrigar em sua lógica o processo ruidoso ("bruit"), caótico ou catastrófico, não como ruído que produz apenas a desordem, mas também, necessariamente, como uma nova organização só possível de ser alcançada devido à capacidade de mediação (ou de “interação") do sistema.

A título de conclusão, defendemos a ideia de que a rememoração da catástrofe é uma constante na arte, no cinema e na cultura porque é um tema íntimo obsessivo. Padecemos do medo do fim. O espírito da morte parece assombrar apenas os que não foram marcados definitivamente pela cicatriz da finitude. A finitude é, portanto, questão de transcendência. Guardamos a memória daquilo a que Edgar Morin chamou "Destino doloroso" (2013). A vida consciente é frágil e minoritária no imenso universo; ela guarda a informação e a lembrança remota dessa fragilidade.

Para Edgar Morin observamos catástrofes em cadeia, na economia, na degradação da biosfera, na multiplicação das armas de destruição, nas convulsões etno-religiosas. Não vivemos uma só catástrofe, mas um conjunto de movimentos com tendências para o desequilíbrio e a instabilidade. Entendemos que o imaginário da catástrofe, pensado a partir da literatura, do cinema, das artes e da comunicação, é um infinito emocional à parte. Italo Calvino mostrou-nos a resiliência, a capacidade de adaptabilidade e de resistência humana diante do tempo e do caos.

A nossa segunda conclusão é a de que o tema da catástrofe supre um pouco o afeto de horror da humanidade atual. É um imaginário que precisa de ser constantemente reatualizado, revisitado, reexplorado para nos comover em direção à necessidade de renascimentos.

A terceira conclusão é a de que o imaginário da catástrofe não é recente, não é individual, não é nacional. É coletivo, transcultural e, em certo sentido, afetivo-poético e mágico. A catástrofe produz uma cadeia de afetos que vai do terror à piedade. Existe nela uma instabilidade permanente e atuante. Dia e noite, atua um princípio de convulsão e harmonia entre as leis universais e os casos particulares, entre os deuses e os homens, entre as formas da natureza e as da cultura, os objetos do mundo e os seres pensantes. A importância desta instabilidade está no fato de que ela parece ser o motor das ações. Sabemos que a catástrofe real não é quando há movimento, mas ao contrário, quando tudo fica estagnado, sem criatividade, sem sentido, sem fundo. A capacidade humana de imaginar e fazer o pior não tem limites. Mas também o contrário. Fugir do caos em direção a uma "ordem de cristal", a Eros ou ao amor de Vug é uma forma de realizar a beleza.

\section{REFERÊNCIAS}

Atlan, H. (1992). Entre o cristal e a fumaça. Ensaio sobre a organização do ser vivo. Rio de Janeiro: Jorge Zahar Editor. 
Baitello Jr, N. (2012). Pensamento sentado. Sobre glúteos, cadeiras e imagens. São Leopoldo: Ed. Unisinos.

Calvino, I. (1992). As cosmicômicas. São Paulo: Companhia das Letras.

Calvino, I. (1995). Novas cosmicômicas. Lisboa: Teorema.

Flusser, V. (2011). Vampyroteuthis infernalis. São Paulo: Annablume.

Castro, G., Galeno, A. \& Silva, J. (2003). Complexidade à flor da pele. São Paulo: Cortez.

Garde, P. (Produtor) \& Von Trier, L. (Realizador). (2011). Melancholia [Filme]. Alemanha/Dinamarca/França/ Suécia.

Maza, A. J. P. (2015). O poder expressivo da teoria dos mundos possíveis nos videojogos: quando as narrações se convertem em espaços interactivos e fictícios. Comunicação e Sociedade, 27, 273-277. http://dx.doi.org/10.17231/comsoc.27(2015).2101

Morin, E. (1987). O Método I - A natureza da natureza. Lisboa: Europa América.

Morin, E. (1997). Meus demônios. Rio de Janeiro: Bertrand Brasil.

Morin, E. (2013). Meus filósofos. Porto Alegre: Sulina.

Nap, H. (Produtor) \& Syberberg, H. (Realizador). (1977). Hitler - Um filme da Alemanha [Filme]. BBC Londres.

Naves, D. (2003). Caos, filosofia e ciência. In G. Castro, J. Silva \& A. Galeno, Complexidade à flor da pele (pp. 81-94). São Paulo: Cortez.

Nestrovski, A. \& Seligman-Silva, M. (2000). Catástrofe e representação. São Paulo: Escuta.

Pelbart, P. P. (2000). Cinema e holocausto. In A. Nestrovski \& M. Seligman-Silva, Catástrofe e representação (pp. 171-183). São Paulo: Escuta.

Pessis-Pasternak, G. (1993). Do caos à inteligência artificial. São Paulo: Unesp.

Platão (2010). Timeu - Crítias. São Paulo: Annablume.

Prigogine, I. (1996). O fim das certezas. São Paulo: Unesp.

Prigogine, I. (1993). Ilya Prigogine: o arquiteto das 'estruturas dissipativas'. In G. Pessis-Pasternak, Do caos à inteligência artificial (pp. 35-50). São Paulo: Unesp.

Prigogine, I. \& Morin, E. (1998). A sociedade em busca de valores. Lisboa: Instituto Piaget.

Prigogine, I. \& Stengers, I. (1997). A nova aliança. Metamorfose da ciência. Brasília: UnB.

Romano, V. (1993). Desrollo y progresso. Por una ecología de la comunicación. Barcelona: Teide.

Sloterdijk, P. (2012). Crítica da razão cínica. São Paulo: Estação Liberdade.

Thom, R. (1983). Paraboles et catastrophes. Paris: Flammarion.

Weaver, W. (1948). Science and complexity. American Scientist, 36, 536-544. 


\section{NOTAS BIOGRÁFICAS}

Gustavo Castro é poeta, escritor e jornalista. Estágio sênior (2015) em Estudos Ibéricos e Latino-americanos pela Universidade de Sorbonne - Paris IV (Bolsa Capes); Pós-doutorado (2011) em Teoria Literária pela Universidade de Brasília (UnB); Doutorado (2002) em Antropologia pela Pontifícia Universidade Católica de São Paulo (PUC-SP), com tese sobre o escritor Italo Calvino (Bolsa Capes). Mestrado em Educação (Bolsa CNPq em Tecnologia Educacional) pela UFRN (1997). Pesquisador voluntário no Instituto de Estudos Brasileiros, da Universidade de São Paulo (IEB-USP). Estuda o imaginário na perspectiva do pensamento complexo. Membro do eixo temático Études Lusophones (EL), do Centre de Recherches Interdisciplinaires sur le Monde Ibériques Contemporains (Crimic/Sorbonne). Coordena o Grupo Siruiz - Estudo em Comunicação e Produção Literária (http://siruiz.com/), na Universidade de Brasília, onde é professor de Estética na Faculdade de Comunicação. Dedica-se na atualidade ao projeto "Perfil biográfico de João Guimarães Rosa (1908-67)". É autor de "O Enigma Orides" (Ed. Hedra, 2015), sobre a poeta Orides Fontela (1940-1998), entre outros.

ORCID: https://orcid.org/0000-0001-7126-6947

Email: gustavodecastro@unb.br

Morada: QNL o7 Conjunto J, Casa 7, Taguatinga Norte, Brasília - DF / 72150-710

Florence Dravet é professora de Estética na Universidade Católica de Brasília. É doutora em Didactologia das Línguas e Culturas, com tese em Comunicação Intercultural, na Universidade de Paris III - Sorbonne-Nouvelle (2002). Fez pós-doutorado em Comunicação, pela Universidade de Brasília,(2011). Atual coordenadora do Programa de Pós Graduação em Comunicação da Universidade Católica de Brasília. Membro do corpo editorial da revista Esferas e da revista Comunicologia. Orienta pesquisas de graduação, iniciação científica e mestrado. Estuda os fenômenos da sensibilidade, do imaginário, do feminino, do corpo e do poético, as tradições afrobrasileiras e a transculturalidade. Coordena o grupo de estudos em Comunicação, linguagem e Poesia do CNPq. É co-organizadora dos livros "Sob o céu da cultura" (Brasília, Thesaurus, Casa das Musas, 2008) e "Saberes da comunicação" (Brasília, Casa das Musas, 2010). É autora dos livros: "Crítica da razão metafórica - mito, magia e poesia na cultura contemporânea" (Brasília, Casa das Musas, 2014) e "Comunicação e Poesia" (Brasília, UnB, 2014) além de vários livros de poesia.

ORCID: https://orcid.org/0000-0002-3822-3627

Email: flormd@gmail.com

Morada: Avenida Jacarandá, Lote 22, Apto. 1011, Águas Claras, Brasília - DF / 71927-540

* Submetido: 02/08/2018

* Aceite: 19/11/2018 